\title{
Principles for place identity enhancement: a sustainable challenge for changes to the contemporary city
}

\author{
M. Sepe \\ IRAT C.N.R.- DPUU University of Naples Federico II, Naples, Italy
}

\begin{abstract}
Globalization and technological development have contributed to accelerated rates of change and transformed spaces in the contemporary urban landscape. The end result is that on the one hand cities, places, itineraries, customs and behavioural patterns have all come to resemble one another, contributing to an increasing urban identity crisis. On the other, the hallmark of most contemporary cities is now simultaneity and fragmentation. The difficulty of decodifying the new urban scene in order for the city to be planned sustainably led to the PlaceMaker method being set up. This is a method of urban analysis and design which both detects elements that do not feature in traditional mapping and which constitute the contemporary identity of the places, and identifies appropriate project interventions.

Starting from these premises, the aim of this paper is to show the PlaceMaker method and the summary of the main experiments which were carried out. The paper concludes with proposal of the " 12 principles for place identity enhancement", designed as checklists for urban projects with place identity at the core.
\end{abstract}

Keywords: place identity, urban design, contemporary city, sustainable principles, PlaceMaker.

\section{Introduction}

The complexity of urban dynamics which are interesting the contemporary city is mainly due to the speeding up of time and changes in the modality of use of urban space. The resulting instability gives rise to situations of transience and transformation, fertile ground for territorial marketing operations characterized 
by a rapid consume of culture. These are often addressed to a predominantly economic return to the detriment of place identity which in turn becomes increasingly hybrid, compromised or hidden.

The sustainability of any place depends on a number of factors which contribute to its liveability, quality and identity $[1,2]$. Pedestrian-intensive areas, in particular urban, cultural and historical poles of attraction, increasingly bear the imprint of globalization, conveying messages which have developed in an uncontrolled manner and are aimed at conveying their users' patterns of thought and action. The presence of a dense mixture of contrasting elements and perceptions can detract from the image of a city $[3,4]$. Furthermore, especially in pedestrian-intensive areas, it can contribute to creating urban decline and a chaotic atmosphere, including increased episodes of street crime.

In order to draft an urban project focusing on the conservation and enhancement of place identity in such areas, which are often especially representative of their respective cities, we need methods of analysis and imaging tools able to identify and represent the urban elements that make up contemporary cities $[5,6]$.

Based on these considerations, this work aims to illustrate the use of the PlaceMaker method $[7,8]$ created in the context of a broader research project under an agreement between the Italian National Research Council (CNR) and the Urban Design and Planning Department of the University of Naples Federico II and for specific IRAT-CNR projects.

PlaceMaker comprises eight phases - five of analysis and three of design and a Phase 0 that consists in constructing the grid required for the operations which are to be implemented later. This method assembles, elaborates and reconstructs the data deriving from surveys based on physical reconnaissance, sensory perceptions, graphical elaboration, photographic and video records, and sets this data against that provided by an overview of expectations, an analysis based on traditional cartography and two questionnaires administered to local inhabitants. The main products are two final complex maps, one first of analysis and one of design, which represent place identity and project interventions in order both to establish a dialogue with local people and support planners and administrators in the sustainable urban construction and transformation.

The concept of place identity showed in this paper is referred to the definition of Lynch [1] "A workable image requires first the identification of an object, which implies its distinction from other things, its recognition as a separable entity. This is called identity, not in the sense of equality with something else, but with the meaning of individuality or oneness".

Furthermore, the aim of this paper is to show the summary of the main experiments which were carried out in the framework of Italian and European research projects. The case studies spawned the " 12 principles for place identity enhancement", which were created from a reasoned set of blueprints for the various experiments. The paper concludes with proposal of those principles, designed as checklists for urban projects with place identity at the core. 


\section{The Placemaker method}

The PlaceMaker method comprises eight phases; five of analysis and three of design (tab.1).

Table 1: $\quad$ PlaceMaker scheme.

\begin{tabular}{|c|c|c|c|}
\hline PHASE & OBJECTIVES & ACTIONS & PRODUCTS \\
\hline 1 & Anticipatory analysis & $\begin{array}{c}\text { Preliminary } \\
\text { observations } \\
\text { made prior to the first } \\
\text { inspection of the place }\end{array}$ & $\begin{array}{l}\text { Map of the preliminary } \\
\text { ideas of the place }\end{array}$ \\
\hline 2 & $\begin{array}{c}\text { Perceptive and } \\
\text { denominative } \\
\text { description of the elements }\end{array}$ & Denominative survey & $\begin{array}{c}\text { Map visualizing the results } \\
\text { obtained } \\
\text { from the survey }\end{array}$ \\
\hline \multirow[t]{2}{*}{3} & \multirow[t]{2}{*}{$\begin{array}{l}\text { Identification with } \\
\text { traditional cartography } \\
\text { of the elements } \\
\text { required for area } \\
\text { description }\end{array}$} & $\begin{array}{c}\text { Perceptive survey } \\
\text { Graphical survey } \\
\text { Photographic survey } \\
\text { Video survey }\end{array}$ & \multirow[t]{2}{*}{$\begin{array}{l}\text { Map with the components } \\
\text { of the site deduced from } \\
\text { analysis of traditional maps }\end{array}$} \\
\hline & & \multirow{2}{*}{$\begin{array}{c}\text { Analysis of traditional } \\
\text { planimetry at urban } \\
\text { scale } \\
\text { Analysis of traditional } \\
\text { planimetry at territorial } \\
\text { scale } \\
\end{array}$} & \\
\hline \multirow[t]{2}{*}{4} & \multirow{2}{*}{$\begin{array}{l}\text { Identification of place } \\
\text { elements perceived by } \\
\text { users of places }\end{array}$} & & \multirow[t]{2}{*}{$\begin{array}{l}\text { Map visualizing the results } \\
\text { of the questionnaire }\end{array}$} \\
\hline & & $\begin{array}{l}\text { Questionnaire for } \\
\text { visitors to } \\
\text { the place }\end{array}$ & \\
\hline \multirow[t]{2}{*}{5} & \multirow[t]{2}{*}{$\begin{array}{c}\text { Processing the } \\
\text { collected information }\end{array}$} & $\begin{array}{l}\text { Overlay of the maps } \\
\text { with the different } \\
\text { elements } \\
\text { observed from the } \\
\text { anticipatory } \\
\text { and effective analysis }\end{array}$ & $\begin{array}{l}\text { Graphic system } \\
\text { construction }\end{array}$ \\
\hline & & $\begin{array}{l}\text { Check of the different } \\
\text { elements observed } \\
\text { from } \\
\text { different analysis tools }\end{array}$ & \\
\hline \multirow{2}{*}{6} & \multirow{2}{*}{$\begin{array}{l}\text { Identification of identity } \\
\text { resources }\end{array}$} & \multirow{2}{*}{$\begin{array}{l}\text { Identification of identity } \\
\text { potential Identification } \\
\text { of identity problems } \\
\text { Identification of identity } \\
\text { qualities }\end{array}$} & Complex map of analysis \\
\hline & & & Map of identity resources \\
\hline 7 & $\begin{array}{l}\text { Identification of identity } \\
\text { resources by users of } \\
\text { places }\end{array}$ & $\begin{array}{l}\text { Questionnaire for } \\
\text { visitors to } \\
\text { the place }\end{array}$ & $\begin{array}{l}\text { Map visualizing the results } \\
\text { of the questionnaire }\end{array}$ \\
\hline \multirow[t]{2}{*}{8} & $\begin{array}{l}\text { Identification of the project } \\
\text { proposal }\end{array}$ & $\begin{array}{c}\text { Overlay and } \\
\text { elaboration of data } \\
\text { collected }\end{array}$ & $\begin{array}{l}\text { Graphic system } \\
\text { construction }\end{array}$ \\
\hline & & $\begin{array}{c}\text { Definition and } \\
\text { localization of design } \\
\text { intervention }\end{array}$ & $\begin{array}{l}\text { Complex map of identity } \\
\text { project }\end{array}$ \\
\hline
\end{tabular}


The first phase of PlaceMaker is devoted to anticipatory analysis aimed at primary investigation of places; after the preliminary choice of the city and of the part(s) to be analyzed, the ideas about that particular area can be described using any type of instrument or tool of expression, using the information known prior to the first inspection. These notes can be represented in different ways and the result of this phase will be a map of the emerging ideas.

The second phase is that of the five surveys. The first, the denominative one, consists in collecting data regarding constructed elements (presence of monuments, buildings, etc.), natural elements (presence of urban green areas, trees, animals etc.), transportation mode (presence or transit of cars, buses etc.), people (presence of tourists, residents, etc.).The localization of all these elements and the kind and amount, expressed as a low, medium or high percentage, are indicated. As well as the denominative data base there is a cognitive one which constitutes a kind of flexible input, where it is possible to insert elements which are not decided previously, but deduced during inspection.

The second survey is perceptive; a survey is carried out of the smell, sound, taste, touch and visual sensations, and of the global perception, focusing on the localization, type, amount (present in low, medium, high percentage) and quality (non-influential, pleasant, annoying. The survey of the amount and quality of the data, the three options regarding, respectively, the percentage of presence and the feelings induced, are intended to summarise the processing of data that can however be extended during collection. The next survey is graphical: it consists in sketching the places; the sketches will represent the area in question according to a visual-perceptive standpoint and will be supported by annotations where necessary. This operation constitutes a preliminary study for the construction of the graphical symbols for the complex map. Photographic and video surveys of the whole study area are carried out, taking care to record facts rather than an interpretation of the places. The product of the five surveys is a map visualizing the results obtained from the different surveys.

The third phase involves the analysis of traditional cartography of the selected sites in the city. The types of maps used in this phase derive from different disciplines and depend on the nature of the place; the study is carried out at the urban scale, in order to identify the characteristic elements and their relationships with that particular area, and at the areal scale, in order to identify the relationships between the site and the whole city. The result of this phase is a map identifying the components required for the site description that can be found only through a traditional planimetric reading.

The fourth phase is that of the questionnaire administered to visitors to the area in order to gain an idea of the place as perceived by those who are not involved in the study and are not specialists in related fields, but only perceive the site as users, at various levels: the inhabitant, the passer-by, the tourist. The questionnaire consists of questions asked on the basis of images of the area or an inspection visit with the interviewee. The information deduced from the questionnaire is transferred onto a map that, like the previous ones, will constitute the basis for the construction of the complex map. 
The fifth phase is that of assembling the collected information. In this phase, we test the maps produced, the congruence of the various collected data, and choose the useful elements to construct the final map. The recorded data represent the basis for the construction of the graphical system of symbols to represent the elements of the urban landscape and the elaboration of the complex map of analysis $[7,8]$.

We then have three design phases. The sixth phase is devoted to surveying identity resources in the study area. During this phase, the complex map of analysis drawn up with the PlaceMaker method is used as a basis to detect the resources available for the project.

The sixth phase is realized through three measures. The first is the identification of the identity potential, namely of the elements of the complex map which characterize the area in question in order to recognize those which may assume a focal role in the project. In this respect, both the comprehensive presence of a specific type of element (e.g. how many points of visual perceptions are present) and the quantity is measured for each of them (e.g. such an element is assigned a certain size of symbol depending on its visual importance: namely medium size $=$ presence of a given element in a medium percentage). Then there is the second action where the identity problems are highlighted. The activities are devoted to observing places in the complex map with the presence of unsustainable elements and annoying points of perception. With the aim of identifying these places the relationship among the different elements in the map need to be observed. An element may be sustainable in itself, for example a shop which sells typical products; but the presence of several of them may create a site with a concentration of businesses which is unsustainable with respect to place identity. The goal is to understand the impact of people, things and activities and relative issues. The third action is the survey of identity qualities.

The actions to be performed here involve noting places within the complex map of analysis with the presence of sustainable elements and points of pleasant perception. The elements which contribute to defining that sustainable place or perception will need to be analyzed. In this case the aim is again to detect the impact of people, things and activities and relative relationships which are sustainable for identity of places. The product is a synthesis derived from interpreting the complex map of analysis where the identity resources available for the project are represented: a sort of map of intents, the first step for the construction of the complex map for the identity project in question.

The seventh phase is the survey of the identity resources by users of places, locals, passers-by and tourists. A questionnaire designed to elicit information emerged from the previous phase will be administered. The questions aim to ascertain whether the data observed until now are consistent with aspirations, desires and thoughts of the users of the area in question and to collect further suggestions and proposals. The product of this phase is the fourth partial map which will represent the identity resources from the perspective of users of places and/or privileged actors. 
The eighth and last phase consists in the overlay of data collected during the previous four phases and identification of the project proposals. In this phase we identify the places around which the project hypothesis to be conducted to enhance the identity resources are focused and the relative interventions. The products of this phase are a suitable system of symbols which represent the project activities and the construction of the complex map for the identity project. This map is the last step in the planning process, where the information contained in the complex map of analysis, after being filtered and transformed into resources, gives rise to proposals for the construction and enhancement of a sustainable place identity [9].

\section{Experiments}

The PlaceMaker method was conceived in 2001 and has been regularly updated since its pilot case studies started in 2002 in urban sites in Europe, Japan and USA. The main users targeted by the method are urban designers and planners, and administrators, while a simplified form of the complex maps is designed for local, citizens, place users and visitors.

As regards administrators and city planners, PlaceMaker enables them to understand, in the framework of the planning process, the potentials and problems relating to any given place, and how the place itself is perceived by its users and residents. The map may be used for specific purposes to redefine the identity and image of a place vis-à-vis initial demand (e.g. historical identity, commercial identity etc...), to assess the compatibility of any activity with its identity or again, if the aim is to restore traditional businesses, to gauge whether such recovery is still in line with current demands. Thus, the data contained in the map may be used to create active indices and reference parameters for gauging project sustainability, such as quality of life or pollution thresholds, or sustainability of identity, through assessment of the elements making up urban identity from the viewpoint of sustainability.

As to the citizens, PlaceMaker will enable them to garner a deeper understanding of their city's identity, feel stronger ties to it, hence protect and safeguard it or play a proactive role by proposing improvements to administrators or participating in planning choices. Lastly, tourists and place users will find the map a tool providing an insight into the city that goes beyond mere identification of major landmarks and captures the complexity of a place identity, including its tangible and intangible elements, both permanent and temporary.

In order to study the urban identity of sites and identify new elements and places, the areas selected are mostly of historical importance and at all events highly representative of the city and of its transformations, alterations and redesign themes. The pilot case studies, carried out in cities such as Naples, Lisbon, Vienna, Boston and Mexico City, focused on areas in the historic centre, with mixed tourist, commercial and residential uses: for instance the Via Calabritto-Piazza Plebiscito-Galleria Umberto I area in Naples [7]; the Rossio quarter in Lisbon; Newbury Street in Boston; and the Pink Zone in Mexico City. 
In these cases, we tested the tools used for the various stages of the study, we checked the time frame and outputs of each phase, and added supplemental tools as needed. Another case study was carried out on the historical centres in the Province of Caserta, Southern Italy, focusing on the prospects for commercial development. This research called attention to the current state of commerce in the historical centres, in order to requalify, commercially and culturally, places which are suffering a gradual decline and abandonment. It was investigated all the components of the urban scenario related to commerce which go to identify these sites, throwing light on the current urban landscape and the elements and "materials" which make it up, the insertion of traders in the historical centre, the patterns of use for the historical centre and its shops, and the overall perception of the place, with its rhythms, vocation and potential.

Additional experimentation was carried out for some more specific cases, such as the two case studies dealing with the historic centre of Sant'Angelo dei Lombardi (Irpinia, southern Italy) which was studied in the context of the Progetto Dimostratore Irpinia promoted by the Regional Centre for Environmental Risk Analysis and Monitoring (AMRA), and the Kitano-cho area in Kobe, Japan. Both areas had suffered from major earthquakes, followed by poorly-conceived reconstruction that disregarded the need to maintain urban and landscape identity, particularly in Irpinia, with the consequence that the population still finds it hard to relate to the new places. Analysis of these cases involved recognition of the complex identity of the sites following reconstruction, an assessment of the extent to which the earthquake still affects current reality, and the review of possible methods for harmonising sustainable rebuilding with the protection of place identity.

A further example concerned the Trevi-Pantheon area in Rome in the framework of the research project "Sustainable enhancement and fruition of Cultural Heritage: incidence and monitoring of anthropic factors" of the National Research Council Institute for Cultural Heritage Conservation and Promotion Rome, and the European Project Culture 2007-2013 "Preserving places. Managing mass tourism, urban conservation and quality of life in historic centres" (Coordinator: ICVBC CNR Rome Division) [8]. In these projects the research focused on questions related to anthropic risk and mass tourism in historic centres. Due to its peculiarities and its emblematic nature in this regard, the Trevi-Pantheon area was chosen, and monitoring for both cases began in 2006. The Trevi-Pantheon route, due to its recent pedestrianization, which is leading to uncontrolled commercialisation to satisfy the needs of mass tourism has decreased in quality and perception of place identity. The aim of the case study was to detect the identity of the places in question as well as their characteristics and potential, and identify cultural sites and appropriate activities in order to mitigate the impact of mass tourism and provide sustainable and integrated fruition and enhancement of the site.

Furthermore, a series of case studies were carried out in pedestrian or semipedestrian thoroughfares in some major European cities - such as the Ramblas in Barcelona [9], the Esplanade area in Helsinki, Oxford Street in London (figs. 1-2) 


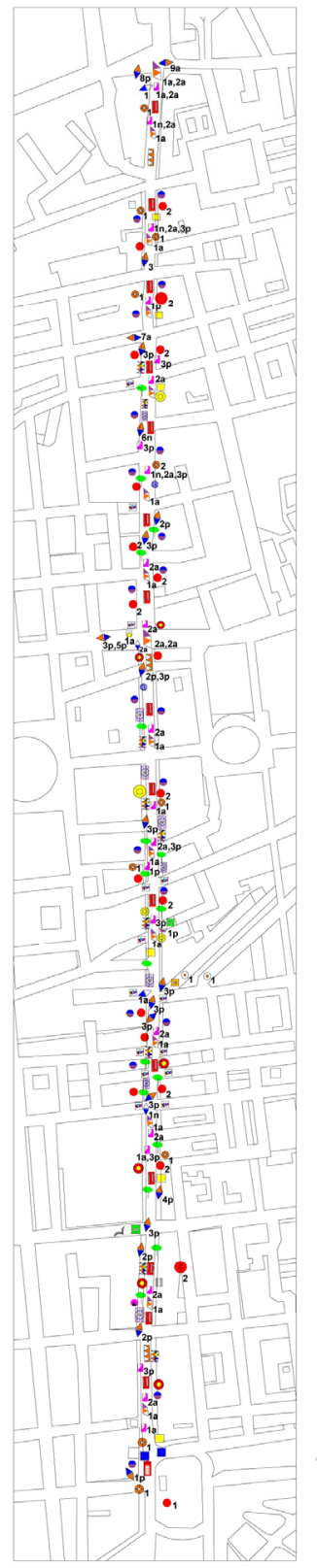

\section{LEGEN D}

place of historical and artistic interest

place with offices and residences

(9) large commercial place

- large commercial place in a historical building

place of commerce selling local souvenirs

- place of commerce selling local and non-local souvenirs

place of traditional socialization
1. South Molton Street and Lane

(6) place of new socialization 1- Fast-food, 2-Store

(क) place-street

empty place

(11) place of limit

A permanent visual perception

1- Marble arch, 2- Building of historical interest, 3- Historical buildings with continuous façade on to the street, 4- Large bright sign, 5-All Souls Church, 6-Skyscraper, 7- Mast with receivers, 8- Dominion Theatre bright advertisement, 9- Perspective buildings

transient visual perception 1- Large advertiscment pancl, 2 Oxford Circus
building site

transient taste perception 1- Temporary pedestrian crossing

- transient smell perception 1- Smell from fast food or cafeteria, 2-Smog, 3- Parfumes from beauty shop

- transient taste perception 1- Typical fruit

transient sound perception - Sounds from means of transport, 2-Noise from construction sites

continual flow of people of different culture

regular pace

WW hectic pace

food kiosk

(a) fruit kiosk

tourist bus kiosk

tocal e non local souvenir kiosk

(4) live statue

@ multimedia information point

Double decker

- Typical telephone box

trees

pigeons

small size of symbol $=$ presence of given

element in slight percentage

medium size of symbol $=$ presence of given

element in medium percentage

large size of symbol = presence of given

element in considerable percentage

n no-influential perception

p pleasant perception

a annoying perception

Figure 1: Oxford Street, London, complex map of analysis. 
The Sustainable City VII, Vol. 21001

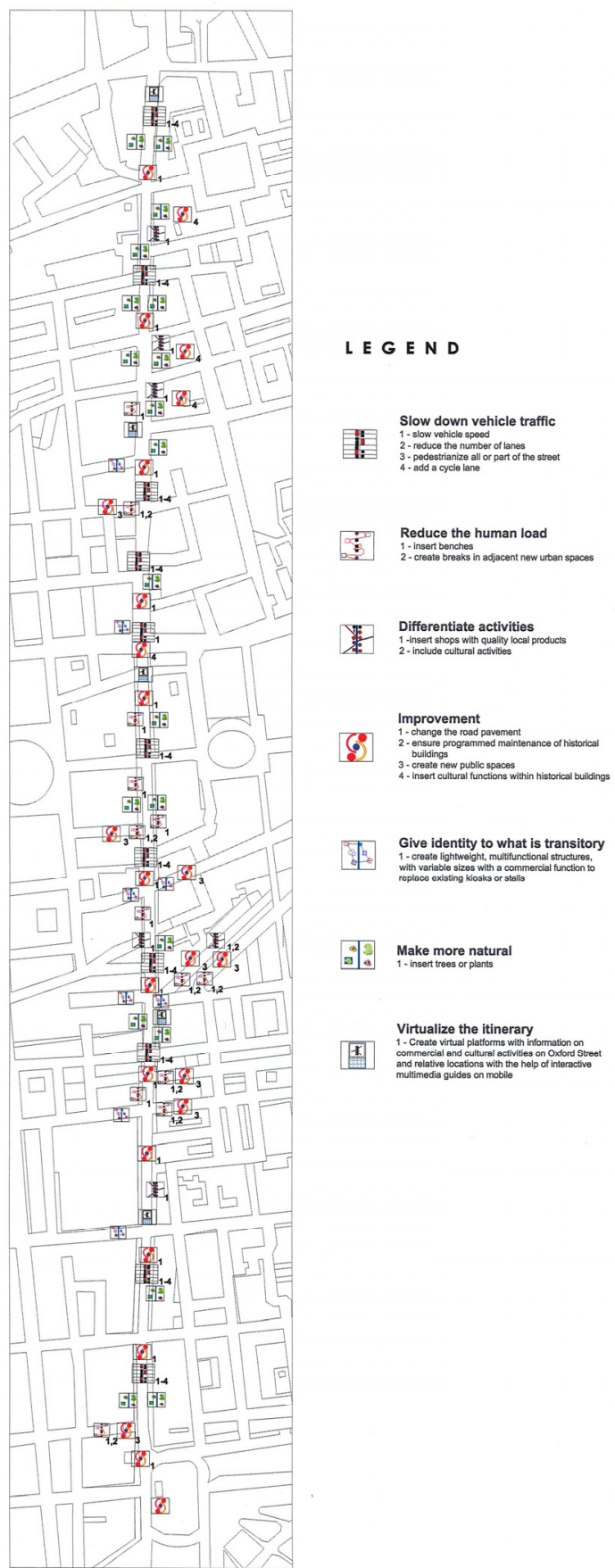

Figure 2: Oxford Street, London, complex map of design. 
- and in California, USA - such as South Broadway in Los Angeles and Market Street in San Francisco.

These studies are located in areas which are dimensionally and geographically quite different, but share a central position and proximity to the core of the city and represent symbolic places for citizens, tourists and users in general. These areas were chosen as they are considered emblematic and as globalization is creating important changes. The aim of the experiments were to ascertain whether the current identity of the places is compatible with their walkability and liveability and whether there are critical points where a sustainable urban design process may be developed to conserve and enhance their identity, and improve their image together with walkability and safety.

\subsection{2 principles for place identity enhancement}

The case studies spawned the "12 principles for place identity enhancement", which are explained below [7-10].

1. Identity resources of a place have to be protected and enhanced so as to give the place in question a distinctive character.

In order to counter the standardization of places which tends to make sites increasingly similar to one another, it becomes ever more necessary to protect identity resources. A site should have elements which make it unique and recognizable. In order to be sustainable, an urban project must be integrated with the identity of places.

2. Place identity has to be determined with ad hoc methods.

Place identity is a complex concept that requires identification of the various factors and elements which make up a place. There are many such elements forming place identity, increasingly compromised by the acceleration of urban change and globalization. In order to make identification as thorough as possible, ad hoc methods have to be used both to detect such complexity and specify guidelines for design.

3. Attention to context is to be understood from a social, environmental and urban perspective.

The context of a place has characteristics not only related to its architecture, urban form and culture, but also to the people who live there, and its environment, understood as natural resources. For sustainability in its broadest sense, respect of all these components is required.

4. The maintenance of buildings, roads and public spaces should be programmed.

Roads and public spaces have to be maintained in the same way as buildings. Programmed maintenance should be performed periodically in order to ensure constant quality of public spaces as well as buildings within.

5. Places should perform functions which do not cause intensive use that can damage site quality.

Monofunctional uses can cause damage to place identity. An example of this is the case of pedestrian thoroughfares of historical importance, used only for business. Combined uses of places should be aimed for, provided they do not compromise place identity. 


\section{Local businesses should be enhanced.}

The intensive use of sites by mass tourism leads to businesses that result in rapid consumption of places at the expense of their culture. It is instead necessary to promote local businesses to ensure residents put down roots where they live.

7. Users of a site should be questioned about place identity during both the survey and design phases, taking different needs into account.

Site users, the prime recipients of urban transformation projects, should be interviewed at various stages in the transformation process of an area, with particular attention to the identity of the place in question. The project will thus be more likely to succeed since various needs will have been taken into consideration.

8. Place identity should be monitored periodically.

Given the great acceleration of the rate of urban change, it is important that place identity be periodically monitored in order to understand evolution and change in time and prevent identity being compromised.

9. Vehicle use in areas with heavy pedestrian throughput should be avoided or slowed down.

In emblematic thoroughfares and historical centres the use of private vehicles is an annoyance factor. In this respect, in such places vehicle speed should be slowed down with appropriate traffic calming measures, or private vehicles should be banned altogether. The use of bicycles and dedicated lanes should where possible be encouraged.

10. The safety of users is paramount.

The users of streets and public spaces in general need to be protected. In this respect, projects should ensure safety both as regards possible collisions with vehicles, with appropriate separation between the different types of flows, and as regards possible criminal acts, encouraging mixed uses of the places in question during the different times of the day.

11. Proper enjoyment of the physical characteristics and natural beauty of the place should be considered a priority.

We need to create places which foster the enjoyment of the elements that make up the history and culture of the place through projects which stimulate knowledge and sustainable use. By the same token, it is necessary to promote the enjoyment of all natural resources which are part of that place.

12. Respect for place identity should be considered a sine qua non within the framework of a project's quality requirements.

Respect for place identity lends quality to a project. Place identity should thus become an essential aspect of urban planning tools so that it becomes a fundamental requisite for project sustainability.

\section{Conclusion}

The paper presented the 12 principles for place identity enhancement, which were created from a reasoned set of blueprints for the various experiments carried out using the original PlaceMaker method for the analysis and design of the contemporary urban landscape. 
The purpose of these principles is to provide urban planning guidelines for the construction of sustainable place identity. The concept of identity is interpreted in line with the definition of Kevin Lynch who refers this concept to the set of characteristics which make a place unique and recognizable. Although the concept is intended as a set of characteristics in a positive sense, it is also possible that these features are not sustainable or are not consonant with the history and culture of the place itself.

Indeed, the set of characteristics may consist, for example, of the shops whose furniture disfigures the ground floors of buildings and prevents appreciation of an urban thoroughfare, but which make that location recognizable. A further example might be the set of elements in a public space which makes that place distinctive but which people in that neighbourhood do not use since it fails to give them a sense of belonging.

The 12 principles aim to provide a check list which a project has to satisfy in order to enhance the identity of the place in question, making sure, however, that place identity is sustainable and is not used for the sole purpose of rapid consumption of intangible heritage. The principles should not be considered static, but dynamic, in keeping with the increasingly rapid rates of change in a place that continually lead to expanding the scope of the concept. These principles in their present form may thus be constantly updated to allow not only for changes in the contemporary city but also for new procedures and requirements in site design.

\section{References}

[1] Lynch, K. The Image of the City, Mit Press: Cambridge, 1960.

[2] Hague C., Jenkins P., (eds.) Place Identity, Participation and Planning, Routledge: Abingdon, 2005.

[3] Butina Watson, G., Bentley, I., Identity by Design, Architectural Press: Oxford, 2007.

[4] Appleyard, D., Livable Streets, University of California Press: Berkeley, 1981

[5] Rose, G., 1995. "Place and identity: a sense of place", Massey D., Jess P., eds, A Place in the world? Place, cultures and globalization, Oxford: Open University/Oxford University Press.

[6] Carmona, M., Heath, T., Oc, T., Tiesdell, S., Public places-Urban spaces, Architectural Press: Oxford, 2010.

[7] Sepe, M. Complex Analysis for the Sustainable Planning and Construction of the Place Identity: the Sensitive Relief Method, International Journal of Sustainable Development and Planning 1(1), pp. 14-31, 2006.

[8] Sepe, M., "Requalifying historic places for sustainable use: a complexsensitive method", HBRC-Housing and Building Research Center-Journal, 4, 2010.

[9] Sepe, M., "PlaceMaker method: planning walkability by mapping place identity" Journal of Urban Design, Routledge 14(4), 2009.

[10] Gehl, J. Cities for People, Island Press: Washington, DC, 2010. 